\title{
AUDIT \\ Consent to emergency detention in Edinburgh
}

\author{
Alistair Deering
}

\begin{abstract}
Circumstances surrounding emergency detention under the Mental Health (Scolland) Act were examined, with particular regard to whether consent was obtained from a third party. Twenty-eight of 100 consecuttive detentions occurred without consent. These patients were more likely to exhiblt agoressive behoviour and be detained by a psychiatric reglstrar or senior registrar. Mental disorder was doubted more offen and detention was less often continued. Reasons given for failing to obtain consent were frequently inadequate and possible explanations are discussed. Increased education and supervision of troinees resulted in a substantiol fall in cases of non-consent in a follow-up sample.
\end{abstract}

Compulsory admission to hospital raises complex issues of civil liberties and a patient's right to treatment (Rachlin et al, 1975). Use of the powers of emergency detention has the fewest safeguards and, unlike other forms of detention. is often carried out by junior medical staff. In Scotland, emergency detention is by means of sections 24 (for out-patients) and 25 (for patients already in hospital) of the Mental Health (Scotland) Act 1984. Although broadly similar to sections 4 and 5 of the Mental Health Act 1983 in providing for a period of 72 hours detention in hospital, the "emergency recommendation" for admission of an out-patient is made by a medical practitioner rather than an approved social worker seeking an "emergency application". Therefore it is possible in Scotland for a doctor acting alone to detain an out-patient under section 24. Consent from a relative or mental health officer (MHO), the Scottish counterpart of the approved social worker, is required "wherever practicable" but the detention is valid providing a statement of the reasons for failure to obtain consent accompany the recommendation. This has the advantage of avolding delays in the patient's admission to hospital in a genuine emergency, but may offer the potential for abuse of the patient's rights.

\section{The study}

I observed a $30 \%$ rise in the number of emergency detentions carried out at the Royal Edinburgh Hospital over five years, and noted that a significant number of detentions took place without consent from a relative or MHO. The catchment population of approximately 450,000 had not increased substantially during this period. A study to examine the circumstances of 100 consecutive emergency detentions to the hospital was carried out in Autumn 1990. The detaining doctor was sent a questionnaire asking the time of detention; if he or she had felt under pressure from a third party to detain the patient; if alternative disposal had been considered; and if the patient's behaviour had been attributable to what the doctor understood by the term "mental disorder". They were also asked if consent had been obtained; who from, and, in the case of an MHO, whether there had been any difficulties with this; and if consent had not been obtained, why not. A semi-structured interview with the doctor was then carried out, wherever possible within seven days of the detention. This included questions about the doctor's previous knowledge of the patient; access to case-note information; the presence of self-harming or violent behaviour at the time of detention; and if the patient had been intoxicated. The patient's casenotes were then studied to obtain demographic details, previous psychiatric history including previous detentions, admission diagnosis and outcome of emergency detention.

\section{Findings}

Twenty-eight patients were detained without consent, and of the remaining 72 cases, an MHO gave consent in 27 and a relative in 45 . The main differences between the no-consent and consentobtained patients are summarised in Table 1 .

The grade of detaining doctor was relevant to whether consent was obtained, with psychiatric registrars/senior registrars significantly more likely to detain patients without consent when compared to psychiatric senior house officers (SHOs), general practitioners or consultant psychiatrists. Twenty of the no-consent cases were detained by registrars/senior registrars, accounting for $42 \%$ of all detentions made by these grades during the study. This compares unfavourably with six cases of no-consent by GPs 
Table 1. Main differences between no-consent and consent-obtained patients

\begin{tabular}{|c|c|c|c|c|}
\hline & \multicolumn{2}{|c|}{$\begin{array}{l}\text { No-consent } \\
(n=28)\end{array}$} & \multicolumn{2}{|c|}{$\begin{array}{l}\text { Consent-obtained } \\
(n=72)\end{array}$} \\
\hline & & (\%) & & (\%) \\
\hline $\begin{array}{l}\text { Detaining doctor } \\
\text { SHO }\end{array}$ & 2 & (7) & 19 & (26) \\
\hline Registrar/Senior registrar & 20 & (72) & 29 & $(40)^{* *}$ \\
\hline Consultant & 0 & & 9 & (13) \\
\hline GP & 6 & (21) & 15 & (21) \\
\hline Violence & 9 & (32) & 9 & $(13)^{*}$ \\
\hline \multicolumn{5}{|l|}{ Threatened } \\
\hline Actual & 10 & (36) & 20 & (27) \\
\hline Self-harm & 11 & (39) & 29 & (40) \\
\hline $\begin{array}{l}\text { Admission diagnosis of major } \\
\text { mental illness (ICD-9 295-298) }\end{array}$ & 16 & (57) & 50 & (69) \\
\hline Prior knowledge of patient & 9 & (32) & 40 & $(56)^{*}$ \\
\hline Mental disorder 'unlikely' & 7 & (25) & 7 & $(10)^{*}$ \\
\hline Continuation of detention & 6 & (21) & 40 & $(56)^{* *}$ \\
\hline
\end{tabular}

${ }^{*}=P<0.05, " *=P<0.01$

(28\% of all GP iletentions), two cases by SHOs (10\% of all SHO detentions) and no cases by consultants ( 0 of 9 cases). Multivariate analysis using logical regression to examine each variable in turn failed to show differences in the patients or circumstances of detentions by registrars/ senior registrars and other grades.

Examination of patient variables revealed those detained without consent were more often aggressive at the time of detention (68\% v. $40 \%)$ ). Threats of violence were more common in the no-consent patients ( $32 \%$ v. $13 \%)$, while violent acts did not differ significantly between the groups (36\% v. 27\%). Threats or acts of selfharm were also similar between groups (39\% v. $40 \%)$. No significant differences were found between groups in admission diagnosis, with $57 \%$ of the no-consent patients having an ICD-9 diagnosis of schizophrenia, manic-depressive or other functional psychosis compared to $69 \%$ of the consent-obtained group. Eleven per cent of the no-consent group and $10 \%$ of the consent-obtained group had a primary admission diagnosis of alcohol abuse/dependence. Demographic data including age, sex and marital status were similar for the two groups, as was a history of previous psychiatric admission (82\% v. $75 \%$ ) and previous detention (53\% v. $44 \%$ ). Time of day detained likewise did not differ, confounding the expectation that consent was less likely to be obtained in the middle of the night. Pressure to detain from a third party was no higher in the no-consent group ( $36 \%$ v. $44 \%$ ), and alternative disposal was considered in only $20 \%$ of each group. The detaining doctor was less likely to have had previous contact with the no-consent patients (32\% v. 56\%), and case-note information was less often available.

The presence of mental disorder was regarded as unlikely more often in no-consent patients $(25 \%$ v. $10 \%)$ and half of all patients in the study in whom mental disorder was doubted were detained without consent. Outcome in the two groups differed, with $21 \%$ of the no-consent patients having their detention continued onto a 28-day section 26 , compared with $56 \%$ of the consent-obtained patients.

The reasons given for fallure to obtain consent fell into three categories:

(a) actual difficulty in obtaining the MHO (two cases, 7\%), e.g. "unable to contact MHO despite repeatedly paging him"

(b) "emergency situation" (16 cases, 57\%), e.g. "patient acutely disturbed, needing physical restraint and urgent sedation", "time was midnight, unable to reveal next of kin", "patient seen in Accident and Emergency Department, no relatives available and it would have involved unnecessary delay", "pressure of time; I had already spent one-and-a-half hours with the patient and was not prepared for further delay in contacting MHO"

(c) ignorance of the act (10 cases, 36\%), e.g. "didn't known MHO avallable at night", "what is MHO?"

\section{Comment}

The Code of Practice to the Mental Health (Scotland) Act 1984 stresses that in many cases 
the decision to detain a patient "may not depend entirely on the medical assessment of the person's mental state" and that "an appraisal of the social circumstances and availability of other care facilities" should be made. "Close cooperation between doctors and other professionals such as Mental Health Officers" is recommended and "wherever possible, the doctor should ask an MHO to interview the person ... to establish whether he will give consent" (Scottish Home and Health Department, 1990). This study finds that $28 \%$ of patients were detained contrary to these guidelines, almost twice the Scottish average for emergency detentions without consent in 1990 (Mental Welfare Commission, 1991). There are circumstances where it is right and proper to detain patients without consent, but such occasions are unlikely to occur twice as frequently in Edinburgh compared to Scotland generally, especially as the psychiatric services are not dispersed over a wide geographical area and there is 24-hour availability of MHOs from the social work emergency duty team.

The patients detained without consent do not have a higher prevalence of major mental illness judging by admission diagnosis and the low number who have their detention continued after 72 hours. They do exhibit more threatening behaviour but are not more likely to commit a violent act. That mental disorder should be doubted more often in no-consent patients is of particular concern. Mental disorder is a prerequisite for detention under the Act, and in cases of doubt the opinion of a fellow mental health professional would seem particularly valuable; this appears often not to be sought. Chiswick (1978), looking at emergency detentions at the same hospital, but under the Mental Health (Scotland) Act 1960, reported the detaining doctor doubted the presence of mental disorder in 23 of 100 cases. The findings from the present study suggest some improvement but still finds one in six patients is detained in the presence of considerable doubt that they are mentally ill. Perhaps clarification of what is meant by "mental disorder" in the Act would be helpful.

General practitioners and SHOs early in their psychiatric training may well be unfamiliar with the recommendations laid down in the Act. However, the high proportion of no-consent detentions carried out by psychiatric registrars/senior registrars suggests ignorance of the Act is not the only reason. In 15 of the 20 no-consent cases detained by registrars/senior registrars, the reason given for failing to obtain consent was of an "emergency situation" where there was no time to contact an MHO. Detention under sections 24/25 is by definition an emergency; therefore this alone does not provide adequate reason to bypass consent. Actual difficulty or delay in obtaining an MHO was uncommon and it may be that middle grade staff resent involving an MHO to 'rubber-stamp' a decision that they have already taken.

In failing to seek consent, however, they risk compromising the spirit of the Act, and the present privilege of detaining a patient without consent in a genuine emergency may be withdrawn. The results of this study were presented at the Royal Edinburgh Hospital in October 1991. In response to the concerns highlighted, several measures were taken including increased education for junior staff about use of the Act and attaching a reminder of the main points of the Act to all section forms within the hospital. I reviewed all emergency detentions between January and August 1992, and of 243 detentions, only 21 were without consent, giving a no-consent rate of $\mathbf{8 . 9 \%}$. This compares favourably with the Scottish average for 1991 of $14 \%$ (Mental Welfare Commission, 1992). There were no changes during this time in the provision of MHO services, nor in the behaviour of GPs, and it appears the no-consent rate was reduced by more than two-thirds by effecting a culture change within the hospital.

\section{Acknowledgements}

The author wishes to thank Dr John Loudon and Dr John Eagles for helpful comments and support, and Ms Marion Campbell for statistical advice.

\section{References}

Chiswick, D. (1978) Pattern of use and attitudes to the Mental Health (Scotland) Act 1960. Unpublished thesis. Edinburgh University.

Mental Health (Scotland) Act 1984, Chapter 36. London: HMSO.

MENTAL Welfare COMmission (1991) Annual Report 1990. London: HMSO.

- (1992) Annual Report 1991. London: HMSO.

RACHIn.. ALVIn, P. \& MinTON, J. (1975) Civil liberties versus involuntary hospitalisation. American Journal of Psychiatry, 132, 189-192.

Scottish Home \& HEalth Department (1990) Code of Practice, Mental Health (Scotland) Act 1984. London: HMSO.

Alistair Deering, Senior Registrar, Royal Cornhtll Hospital, Cornhill Road, Aberdeen AB9 2ZF (formerly Clinical Research Fellow, Royal Edinburgh Hospital) 